\title{
DAMPAK PERNIKAHAN USIA DINI (Analisis Feminis Pada Pernikahan Anak Perempuan Di Desa Cibunar Kecamatan Cibatu Kabupaten Garut)
}

\author{
Rovi Husnaini ${ }^{1}$, Devi Soraya ${ }^{2}$ \\ Universitas Muhammadiyah Bandung, \\ UIN Sunan Gunung Djati Bandung \\ Email: rovihusnaini@gmail.com, Devisoraya2000@gmail.com
}

\begin{abstract}
Abstrak
Fenomena pernikahan usia dini pada akhir ini angkanya semakin meningkat. Di Indonesia terutama daerah pedesaan yaitu di Desa Cibunar Kecamatan Cibatu Kabupaten Garut. Pernikahan usia dini di desa ini sangatlah sering terjadi, baik orang yang sudah mampu maupun orang yang belum mampu untuk melaksanakan pernikahan. Pernikahan dini yang berlangsung sejak dulu dan masih bertahan sampai sekarang. Bagi masyarakat pernikahan usia dini tidak hanya terjadi karena faktor ekonomi saja, tapi ada faktor lain yaitu kurangnya pendidikan orang tua serta anak. Hingga pernikahan usia dini menjadi solusi bagi mereka. Penelitian ini bertujuan untuk mengetahui dampak pernikahan usia dini bagi anak perempuan melalui analisis feminisme liberal yang mengkategorikan perempuan dan laki-laki memiliki hak dan kesempatan dan pendidikan yang sama. Dengan teori Wollstonecraft, bahwa "inferioritas" perempuan sebagai agen rasional disebabkan pendidikan yang rendah. Pendidikan hanya diprioritaskan hanya untuk laki-laki. Dalam hal ini langkah-langkah yang ditempuh oleh penulis dalam melakukan penelitian pertama, melalui pencarian data objektif dengan cara observasi, studi dokumentasi dan wawancara (interview). Kedua melalui studi kepustakaan yaitu penelaahan buku-buku yang berhubungan dengan masalah penelitian. Hasil penelitian menunjukan bahwa, faktor penyebab pernikahan dini di Desa Cibunar yaitu (1) Faktor ekonomi, (2) Faktor rendahnya dan kesadaran terhadap pentingnya pendidikan, (3) Faktor lingkungan mereka tinggal. Dampak yang timbulkan dari pernikahan usia dini di desa cibunar kecamatan cibatu kabupaten garut yaitu: (1) Ekonomi, (2) Kesehatan, (3) Pandangan masyarakat terhadap pelaku pernikahan usia dini, sedikit permasalahan muncul karena cerminan kebiasaan perempuan itu sendiri seperti malas, bangun tidur siang, pemalu dan lain sebagainya.
\end{abstract}

Kata kunci: Dampak pernikahan usia dini, feminisme, pernikahan dini. 


\section{Abstract}

The number of early marriage phenomena has recently increased. In Indonesia, especially rural areas, namely in Cibunar Village, Cibatu District, Garut Regency. Early childhood marriages in this village occur very often, both those who are able and those who are not able to carry out marriages. Early marriages that lasted a long time ago and still survive today. For the community, early marriage does not only occur due to economic factors, but there are other factors, namely the lack of education of parents and children. Until early marriage is a solution for them. This study aims to determine the impact of early childhood marriage for girls through analysis of liberal feminism which categorizes women and men as having the same rights and opportunities and education. With Wollstonecraft's theory, the "inferiority" of women as rational agents is due to low education. Education is only prioritized only for men. In this case the steps taken by the author in conducting the first research, through the search for objective data by means of observation, documentation study and interviews (interview). Second, through literature study, namely the study of books related to research problems. The results showed that the factors causing early marriage in Cibunar Village were (1) economic factors, (2) low factors and awareness of the importance of education, (3) environmental factors they lived in. The impact that arises from early marriage in Cibunar village, Cibatu sub-district, Garut district, namely: (1) Economy, (2) Health, (3) Public views on early marriage actors, a few problems arise because of reflections of women's habits such as being lazy, getting up. naps, shy and so on.

Key words: Impact of early marriage, feminism, early marriage.

\section{A. Pendahuluan}

Undang-Undang Nomor 1 tahun 1974 menegaskan bahwa usia minimal untuk melakukan pernikahan bagi perempuan ialah 16 tahun. Namun, menurut hasil laporan penelitian BKKBN pada tahun 2014, rasio pernikahan dini di Indonesia, terkhusus daerah pedesaan masih cukup tinggi, yakni 67 per 1000 pernikahan. Angka ini masih terbilang tinggi bagi praktik pernikahan dini di Indonesia. ${ }^{1}$

Menurut Dr.Ahmad Yasa, SPOG yakni spesialis kebidanan dan dan kandungan dari Rumah Sakit Balik Papan, menegaskan bahwa pernikahan dini berbahaya bagi kesehatan sekaligus amat beresiko bagi anak, meskipun ia telah mengalami menstruasi pada umur kurang dari 15 tahun. Dampak dari pernikahan dini itu sendiri bisa dilihat dari potensi

\footnotetext{
${ }^{1}$ Fenoena pernikahan dini dan solusinya https://student.cnnindonesia.com/inspirasi/20160318142526-322-118315/fenomenapernikahan-dini-dan-solusinya/ diakses ada tanggal 25 februari 2018
} 
munculnya penyakit yang berkaitan dengan kebidanan dan kandungannya, terkhusus beresiko pada kanker mulut rahim dan infeksi kandungan. Masalah lainnya berkaitan dengan sel pertumbuhan anak, yang justru matang pada saat usia 19 tahun. ${ }^{2}$ Kemudian, masalah lainnya berkaitan dengan resiko kematian bayi yang mencapai $50 \%$ pada praktik pernikahan dini (WHO, 2012).

Pernikahan dini sendiri diartikan sebagai praktik pernikahan yang dilakukan di bawah ketentuan usia standar perundang-undangan. Selain itu pernikahan dini sering disebut juga sebagai dispensasi nikah, yang berarti mengacu pada pasangan yang ingin menikah di bawah standar usia. ${ }^{3}$

Pada zaman modern, praktik pernikahan dini masih saja dipraktikan oleh beberapa daerah terkhusus di daerah Desa Cibunar. Di desa ini ditemukan terdapat 15 orang yang telah melakukan praktik pernikahan dini. ${ }^{4}$

\section{B. Metode Penelitian}

Penilitian ini dilakukan di daerah Desa Cibunar Kecamatan Cibatu Kabupaten Garut. Latar belakang menentukan tempat ini karena di Desa Cibunar sering kejadian gejala sosial yang keleluasan besar langka terjadi ditempat lain, hingga juru tulis menganggap tergiring akan membahas serta meneliti gejala tersebut, diantaranya pernikahan pada anak perempuan tersebut.

Penelitian ini sendiri didasarkan pada metode kualitataif. Metode kualitatif sendiri ialah cara penelitian yang mampu menghasilkan data baik dari ucapan atau perilaku teramati secara deskriptif. ${ }^{5}$ Metode penelitian kualitatif bertujuan untuk dapat menggambarkan realitas secarasistematis dengan sebuah penyusunan yang akurat. Proses kerja metode ini ialah dengan cara menggambarkan objek atau subjek penelitian, lalu dianalisis, sampai kemudian diperbandingkan dengan kenyataan yang terjadi saat ini, lalu ditemukan sebuah pemecahan atasnya. ${ }^{6}$

\footnotetext{
2 Alipoetry "Dampak Positif dan Negatir Pernikahan Usia Dini" http://aliranim.blogspot.co.id/2012/08/dampak-positif-dan-negatif-pernikahan.html diakses pada tamggal 20 Maret 2018

${ }^{3}$ Nurmilah Sari, Skripsi Hukum, "Dispensasi Nikah Di Bawah Umur (Studi Kasus Pengadilan Agama Tangerang Tahun 2009-2010)" Jakarta: Universitas Islam Negeri Syarif Hidayatullah ${ }^{4}$ Wawancara dengan pak Wardoyo (Babinsa Desa Cibunar) pada tanggal 15 januari 2018

${ }^{5}$ Lexy J. Moeloeng, Metodologi Penelitian Kualitatif, (Bandung: PT Remaja Rosdakarya, 2006) 4

${ }^{6}$ Supardi, Metodologi Penelitian Ekonomi dan Bisnis, (Yogyakarta: UII Press, 2005) 28
} 
Pertimbangan peneliti untuk memilih metode ini ialah, karena metode penelitian kualitatif dapat menangkap kenyataan yang ganda, kemudian metode ini menunjukan hubungan antara peneliti dengan objek penelitian secara langsung. Lebih jauh, metode ini lebih peka yang dapat menyesuaikan diri, dan juga mempertajam pengaruh bersama pola-pola nilai yang ada di hadapan peneliti. ${ }^{\text {? }}$

Demi mendapatkan data, peneliti di sini menggunakan metode pengumpulan daya. Metode ini berarti teknik yang digunakan peneliti untuk mendapatkan data. Lalu ada juga instrument pengumpulan data, yakni alat bantu yang dapat membantuk pengumpulan data itu sendiri, agar dalam proses kegiatannya menjadi lebih sistematisn serta lebih mudah. ${ }^{8}$ Adapun metode pengumpulan data terdiri dari:

1. Teknik Observasi: Observasi teknik mengumpulkan data dengan cara mengamati serta mencatat prilaku dan kondisi objek. ${ }^{9}$

2. Teknik Wawancara Mendalam: Wawancara berkaitan dengan pengumpulan data dengan berkomunikasi secara langsung dengan responden. ${ }^{10}$

3. Teknik Dokumentasi: Dokumen berarti catatan peristiwa yang telah lampau. Dokumentasi bisa bberwujud gambar, karya-karya monumental atau tulisan seseorang. ${ }^{11}$

4. Triangulasi: Triangulasi dipergunakan untuk mendapatkan kebasahan dan kredibilitas data. Triangulasi difungsikan untuk pengecekan serta memperkaya data. Teknik ini juga digunakan untuk menaring data melalui penyilangan informasi yang didapat supaya data yang diperoleh lebih sesuai dan lengkap dengan harapan. Sehabis memperoleh data yang jenuh, yakni keterangan yang diperoleh dari sumber data telah sama, maka data yang diperoleh semakin kredibel. ${ }^{12}$

\footnotetext{
${ }^{7}$ Ahmad Tanzeh dan Sugiyono, Dasar-dasar Penelitian, (Surabaya: Elkaf, 2006), 116

${ }^{8}$ Ridwan, Statistika Untuk Lembaga dan Instansi Pemerintah/Swasta, (Bandung: Alfabeta, 2004), 137

${ }_{9}$ Abdurrahman, Fatoni, Metodologi, Penelitian dan Teknik Penyusunan Skripsi, (Jakarta: PT. Rinekha Cipta, 2006) 104-105

${ }^{10}$ Nural Zuriah, Metodologi Penelitian Sosial dan Pendidikan, 92

${ }^{11}$ Sugiyono, Metode Penelitian Kuantitatif, 244

${ }^{12}$ Data diambil dari laporan penyelenggaraan pemerintah Desa Cibunar Maret 2018, 4
} 


\section{Hasil Penelitian}

a. Luas wilayah Desa Cibunar

Desa Cibunar tedapat 3 dusun, setiap dusun terdiri dari 14 Rukun Warga (RW) dan setiap RW memiliki 52 Rukun Tetangga (RT). Dengan luas tanah 2.078,85 Ha dengan potensi perangkatnya terdiri dari seorrang kepala desa (kades), sekertaris desa (sekdes), 3 orang kaur, 3 kadus dan 3 kasi.

o Sebelah Timur: Desa Karyamukti dan Desa Sukalilah

o Sebelah Selatan: Desa Keresek dan Desa Padasuka

o Sebelah Barat: Kecamatan Cibiuk

o Sebelah Utara: Desa Sindangsuka dan Mekarsari.

Lokasi penelitian ialah Desa Cibunar, Kecamatan Cibatu, Kabupaten Garut, Provinsi Jawa Barat. Letak topografis tanahnya datar, dengan lahan sebagian besar dimanfaatkan oleh masyarakat untuk bercocok tanam atau persawahan dan sebagian besar besar masyarakatnya adalah petani dan pedagang.

\section{Tabel 1. Kondisi Desa}

Dalam termasuk pada beberapa dusun, jarak tiap dusun cukup jauh sehingga diperlukan kendaraan bermotor untuk menempuhnya, entah itu menggunakan motor seperti ojek, atau mobil seperti angkot. Jarak antar Desa Cibunar dengan kantor permerintahan bisa dibilang cukup jauh, karena Kabupaten Garut mempunyai 42 kecamatan dari 417 desa dan 21 kelurahan.

\begin{tabular}{|r|l|l|}
\hline No & Kondisi Desa & Letak \\
\hline 1. & Subur & $200,00 \mathrm{Ha}$ \\
\hline 2. & Tidak subur & $158,00 \mathrm{Ha}$ \\
\hline
\end{tabular}


Tabel 2. Jarak Desa ke Kota

\begin{tabular}{|c|l|l|l|}
\hline \multicolumn{1}{|c|}{ No } & Keterangan & Jarak & $\begin{array}{l}\text { Waktu } \\
\text { tempuh }\end{array}$ \\
\hline 1. & $\begin{array}{l}\text { Dari desa ke } \\
\text { kecamatan }\end{array}$ & $4 \mathrm{~km}$ & 30 menit \\
\hline 2. & $\begin{array}{l}\text { Dari desa ke } \\
\text { kabupaten }\end{array}$ & $17 \mathrm{~km}$ & 60 menit \\
\hline 3. & $\begin{array}{l}\text { Dari desa ke } \\
\text { provinsi }\end{array}$ & $56.6 \mathrm{~km}$ & 240 menit \\
\hline
\end{tabular}

Tabel di atas menandakan bahwa Desa Cibunar Kecamatan Caibatu Kabupaten Garut Provinsi Jawa Barat, anatara desa ke kecamatan yaitu 4 km dalam waktu tempuh \pm 30 menit, jarak dari Desa Cibunar ke Kabupaten 17 $\mathrm{km}$ kabupaten dalam waktu tempuh \pm 60 menit, dan jarak dari Desa Cibunar ke Provinsi $56.6 \mathrm{~km}$ kabupaten dalam waktu tempuh \pm 240 menit. Untuk sampai di sana memerlukan kendaraan.

b. Pendidikan

Program menempuh pendidikan 9 tahun di Desa Cibunar sekarang ini, belum terlaksanakan. Masih ada anak-anak Desa Cibunar yang tidak melanjutkan pendidikan hingga jenjang yang tinggi. Alasannya karena pendidikan dan pengetahuan orang tua yang kurang. Sehingga, orang tuaorang tua hanya menyekolahkan anaknya hingga jenang sekolah dasar, yang mana setelah itu diharapkan akan membantu orang tuanya. Sementara itu terdapat anak yang tidak begitu betah tinggal di desa, sehingga memutuskan untuk pergi ke kota untuk menjadi buruh pabrik atau bekerja di luar kota.

Demi meningkatkan kualitas masyarakat setempat, pemerintah sendiri telah menyajikan sarana pendidikan bagi warga desa Cibunar. Sarana pendidikan yang terdapat di Desa Cibunar:

Tabel 3. Sarana pendidikan yang terdapat di Desa Cibunar

\begin{tabular}{|l|l|l|l|l|}
\hline No & $\begin{array}{l}\text { Tingkat } \\
\text { Gedung }\end{array}$ & Gedung & Guru & Murid \\
\hline 1. & TK & 0 & 2 & 23 \\
\hline 2. & SD & 6 & 36 & 435 \\
\hline 3. & SMP & 2 & 8 & 362 \\
\hline 4. & SMA & 1 & 0 & 0 \\
\hline
\end{tabular}


c. Musim dan kemarau.

Desa Cibunar hanya mengalami dua musim, yakni musim hujan

\section{d. Pola penggunaan Lahan Pertanian}

1. Pada musim penghujan, para petani biasanya menanam padi, sedang pada musim kemarau mereka menanam palawija. Bahkan tak jarang ada juga yang memaksakan diri untuk menanam padi.

2. Lahan pekarangan biasanya ditanami tanaman-tanaman kecil, misalnya tanaman obat atau kayu untuk bahan bangunan.

e. Kondisi Desa Cibunar (Kependudukan)

Desa Cibunar yang luasnya 2.078,85 Ha, yang terbagi ke dalam beberapa bagian desa ditempati oleh sekitar 8139 orang/ 2622 KK.

Tabel 4. Jumlah Penduduk Bedasarkan Jenis Kelamin

\begin{tabular}{|l|l|l|}
\hline NO & $\begin{array}{l}\text { KENIS } \\
\text { KELAMIN }\end{array}$ & JUMLAH \\
\hline 1. & Laki-laki & 4223 orang \\
\hline 2. & Perempuan & 3916 orang \\
\hline & umlah & 8139 orang \\
\hline
\end{tabular}

Tabel di atas menunjukan bahwa penduduk Desa Cibunar kurang lebih terdapat 8139 orang, yang terdiri dari laki-laki 4223 orang dan perempuan 3916 orang. Di antara mereka ada yang sudah menikah, dan ada yang belum.

b) Mata Pencaharian

Desa Cibunar yang diduduki oleh 8139 orang semuanya bermata pencaharian yang berbeda-beda tapi didominasi oleh petani. Di antara mereka ada yang bekerja sebagai pedagang, industry kecil, jasa, peternak, PNS dan buruh. Lalu daerah pedesaan biasanya dikenal sebagai daerah yang masih banyak memiliki lahan pesawahan yang biasanya ditanami padi, kacang, sayur, jagung, buah dan lain-lain. 
Tabel 5. Jumlah Penduduk Menurut Mata Pencaharian

\begin{tabular}{|l|l|l|}
\hline NO & PEKERJAAN & UMLAH \\
\hline 1. & PEDAGANG & 361 orang \\
\hline 2. & $\begin{array}{l}\text { PETANI/BURUH } \\
\text { TANI }\end{array}$ & 522 orang \\
\hline 3. & PETERNAK & 4 orang \\
\hline 4. & WIRASWASTA & 433 orang \\
\hline 5. & PNS & 36 orang \\
\hline 6. & POLRI & 3 orang \\
\hline 7. & TNI & 21 orang \\
\hline 8. & PENSIUNAN & 188 orang \\
\hline 9. & DOKTER/PERAWAT & 3 orang \\
\hline 10. & PENGEMUDI & 5 orang \\
\hline 11. & LAIN-LAIN & 6383 orang \\
\hline & JUMLAH & 8139 orang \\
\hline
\end{tabular}

Dapat disimpulkan bahwa Desa Cibunar tidak memiliki gedung TK dengan guru 2 orang dan murid 23 orang, SD (Sekolah Dasar) terdapat 6 bangunan, 36 tenaga pengajar dan 435 siswa/siswi, serta SMP mempunyai 2 gedung dan tenaga pengajar 8 orang 362 siswa/siswi, dan SMA berjumlah 1 gedung.

\section{c) Agama}

Walaupun berbagai macam agama di Indonesia, penduduk bebas untuk memilih agama menganut kepercayaannya masing-masing. Tapi, di Desa Cibunar semua penduduk memeluk agama mayoritas orang Indonesia, yakni Islam. 


\section{Pembahasan}

\section{Faktor-Faktor Yang Menyebabkan Pernikahan Usia Dini di Desa Cibunar Kecamatan Cibatu Kabupaten Garut.}

\section{a. Faktor Ekonomi}

Faktor ekonomi merupakan dorongan para orang tuauntuk menikahkan anaknya secara diri, karena mereka menganggap bahwa pernikahan dini akan meringankan beban dan tanggungan keluarga. Karena anggapan mereka dengan menyelenggarakan pernikahan usia dini akan menerima sumbangan berupa kebutuhan pokok semisal beras dan uang yang bisa dipergunakan untuk sehari-hari dalam beberapa kurun waktu lumayan lama.

Masyarakat yang ada di Desa Cibunar tidak semua dapat memenuhi atau mencukupi kebutuhan keluarga mereka, dikarenakan kebutuhan antara keluarga yang satu dan keluaraga yang lain itu berbeda. Desa Cibunar masyarakatnya bermata pencahariann beragam, yaitu sebagai petani, pedagang, buruh, peternak, PNS, industri kecil dan jasa. Dan Desa Cibunar kebanyakan bermata pencaharian sebagai petani.

Dapat dilihat bahwa perekonomian di Desa Cibunar umumnya hanya mengandalkan pertanian saja. Dan pernikahan usia dini kebanyakan dilakukan oleh masyarakat yang tergolong perekonomiannya rendah, hingga pernikahan usia dini menjadi sebuah solusi atau jalan keluar dari himpitan ekonomi yang mereka sedang jalani.

\section{b. Faktor Rendahnya dan Kesadaran Terhadap akan Pentingnya Pendidikan}

Ada faktor lain yang menyebabkan anak menikah usia dini, yaitu kurangnya kesadaran orang tua terhadap pentingnya pendidikan. Minimnya pendidikan orang tua, yang hanya mengenyam pendidikan hanya sampai sekolah dasar (SD) atau tidak sekolah sama sekali, menyebabkan para orang tua tidak mengerti pernikahan yang ideal itu seperti apa. Orang tua ini biasanya hanya melihat anaknya "sudah besar" sehingga mereka langsung menikahkan anaknya, karena dianggap sudah mencapai waktunya.

Orang tua yan menikahkan anaknya disebabkan karena mereka mereka kurang mengerti dan kurang faham akan pernikahan ideal itu seperti apa. Demikian juga dengan sang anak yang hanya mengenyam pendidikan yang rendah, berdampak pada minimnya informasi yang didapat olehnya. Misalnya mengenai pendidikan wajib 9 tahun, tapi warga Desa Cibunar 
belum bisa melaksanakan program tersebut. Karena orang tua masih banyak yang tidak memerdulikan betapa pentingnya pendidikan anak mereka.

\section{c. Faktor Lingkungan Mereka Tinggal}

Faktor lain ialah faktor lingkungan yang mereka tinggal sangat mempengaruhi pemikiran orang tua serta anak yang dapat menyebabkan mereka melangsungkan pernikahan usia dini.

Pernikahan pada Desa Cibunar telah membudaya di masyarakat, ia telah dipraktikan sekian lama sampai hari ini. Pernikahan diselenggarakan setidaknya setelah melakukan lamaran.

\section{Dampak dari Pernikahan Usia Dini di Desa Cibunar Kecamatan Cibatu Kabupaten Garut.}

\section{a. Ekonomi}

Faktor ekonomi dan sosial selalu menjadi sorotan dalam kasus pernikahan dini. Tak heran jika praktik pernikahan dini, terjadi justru di daerah-daerah yang ekonominya tertinggal. Dalam konteks itu, para orang tua mendorong anak perempuan mereka walaupun mereka belum memenuhi syarat pernikahan ideal. Faktor ekonomi inilah yang kemudian memaksa para orang tua untuk tidak menyekolahkan anaknya ke tingkat yang lebih tinggi.

Dapat dilihat bahwa perekonomian di Desa Cibunar umumnya hanya mengandalkan pertanian saja. Dan pernikahan usia dini kebanyakan dilakukan oleh masyarakat yang tergolong perekonomiannya rendah, hingga pernikahan usia dini menjadi sebuah solusi atau jalan keluar dari himpitan ekonomi yang mereka sedang jalani.

Dapat kita lihat bahwa keadaan ekonomi yang dialami setiap objek atau narasumber pertama, yaitu "Ekonomi yang dialami ketika awal menikah, ES tidak menentu kadang ada kadang tidak suami ES yaitu AS sebagai petani hanya cukup untuk makan saja, hingga sampai ES berkerja dan meninggalkan anak dan ditinggal sama neneknya".

\section{b. Kesehatan}

Secara biologis, seorang anak belum mengalami kematangan organ reproduksinya, sehingga huungan seksual dengan lawan jenis akan beresiko. Jika dipaksakan, hal tersebut akan menyebabkan depresi, perobekan yang luas, infeksi, trauma, kanker rahim dan neuritis, yang tentu saja berbahaya 
bagi jiwa ibu serta anak. Dari kesehatan mereka tedapat dari 2 narasumber yaitu narasumber ke dua, yaitu yang mana mereka mengalami kesehatan yang tidak normal setelah melahirkan:

"Begitu jarak 2 minggu melahirkan UA mengalami sesak hingga terasa setiap malam selama 2 minggu karena kata dokter ini efek dari melahirkan"

dan narasumber ketiga yaitu:

"HS dikaruniai dua anak yang lahir bayi pertama, bayi prematur"

Faktor lain selain kesehatan adalah faktor psikologis. Hal ini sangat penting karena berkaitan dengan kedewasan psikis seseorang. Pernikahan dini tentu akan sangat beresiko, karena belum ada kematangan emosional. Kematangan emosional itu sendiri tentu terbentuk juga seiringan dengan usia seseorang. Dalam konteks pernikahan dini, anak-anak ini akan selalu menghadapi masalah alih-alih dengan tawaran solutif, malah mendekatinya secara emoisonal.

Kurangnya pendidikan menyebakan emosi mereka tida stabil, semakin dewasa dan semakin tinggi sekolah maka akan semakin mampu mengolah dan mengimbangi emosionalitas yang mereka rasakan dengan akal sehat mereka sendiri. Pertengkaran yang sering terjadi, merupakan indikasi dari ketidakmatangan psikis mereka, alias belum mampu mengontrol emosi. Pertengkaran sendiri memang hal yang biasa dalam sebuah rumah tangga, permasalahan yang sering dialami perempuan yang melaksanakan pernikahan usia dini yaitu pada umumnya penyesuaian masing-masing karakter.

\section{c. Pandangan Negatif Masyarakat terhadap Pelaku Pernikahan Usia Dini}

Dalam ajaran Islam, Tuhan dipercayai telah menciptakan manusia yang terdiri dari perempuan dan laki-laki, bersuku-suku dan bangsa agar saling mengenal dan memberi manfaat. (Q.S 49;13). Islam menghendaki adanya perlindungan atas individu dan kelompok, lalu Islam juga memberi kehendak bebas yang sesuai porsi agar tetap seimbang, Islam juga mengatur hak dan kewajiban individu dan kelompok beserta keseimbangannya.

Pada mulanya, pasangan pernikahan dini menjalani pernikahan dengan biasa. Sampai akhirnya mereka mendapatkan masalah ketika kebiasaan-kebiasaan kanak-kanak muncul, seperti bangun tidur yang kesiangan, pemalu, malas dan lain-lain. Lalu, mereka mesti mengurusi kehidupan rumah tangga, di mana kesiapan jasmani dan rohai belum matang, dan belum bisa dipahami oleh pasangan yang melaksanakan 
pernikahan usia dini karena dalam bertetangga karena masih anak-anak dan belum mempunyai pemahaman dan pengalaman.

\section{Analisa}

Pada informan ke satu, menurut feminisme liberal bahwa Friedan dalam bukunya yang kedua menganjurkan agar peempuan meninggalkaan kesan "superioritas" dan beranjak pada tahap ke yang lebih baik yaitu disebut tahap ke dua. Yaitu kalangan femini untuk bekerja sama dengan laki-laki. Ia mengajak perempuan untuk melepaskan mistik dari feminis yang mengabaikan kebahagiaan cinta dan rumah tangga serta tidak terjebak oleh mistik feminin, yang mendefinisikan perempuan hanya ada disekitar rumah hubungannya dengan suami dan anak-anak.

Pada informan ke dua dan ketiga bahwa dalam feminisme liberal yang terbagi pada dua aliran. Yang pertama, adalah feminisme liberal yang menekankan bahwa negara mesti menjamin kebebasan sipil (hak memilih, milik, kebebasan bereskpresi dan berserikat, dan lain semacamnya). Sedang yang kedua, adalah feminism liberal yang berorientasi pada kesejahteraan sosio-ekonomi.

Menurut feminisme liberal pada Informan keempat, yaitu ibu $\mathrm{MH}$ yang melakukan pernikahan dini. Yaitu anak dari ibu Ibu RH bapak AN. Dan dikaruniai dua orang anak. "Menurut $\mathrm{MH}$ pernikahan adalah kebahagiaan, dimana MH mempunyai satu orang anak. Faktor penyebab $\mathrm{MH}$ menikah adalah hampir rata-rata yaitu karena ekonomi yang kurang untuk mencukupi kebutuhan hidup yang $\mathrm{MH}$ jalani. Akhirnya $\mathrm{MH}$ mengambil keputusan untuk menikah padahal usia masih dini. Tetapi pada kenyataannya $\mathrm{MH}$ tidak lama menikah dan berlangsung perceraian karena $\mathrm{MH}$ belum dewasa merasa ingin menang sendiri, ekonomi yang belum mencukupi kehidupannya, dan faktor lain yang menyebabkan $\mathrm{MH}$ bercerai dengan suami adalah suaminya galak suka melakukan kekerasan terhadap objek". Taylor Mill menerima pandngan tradisional bahwa ikatan internal ibu dan anak adalah lebih kuat dari pada bapak dan anak. Dan berasumsi bahwa ibulah yang wajib mengasuh anak jika terjadi perceraian. Mill mendorong pasangan untuk menikah dan mempunyai anak Pada usia yang lebih matang. Serta hidup dalam keluarga besar atau di dalam situasi seperti dalam komunitas.

Pada informan kelima"RA menyadari dampaknya karena ketika kebebasan sudah tidak di tangan maka RA harus fokus mengurus anak dan suami dan menjadi ibu rumah tangga seperi burung dalam sangkar" seperti feminisme liberal Wolistonecraft wanita adalah "peliharaan" yang telah merelakan moralitas, kesehatan, dan kenikmatan, serta kekuasaannya demi 
suaminya, supaya mereka tidak keluar rumah yang dapat menyebabkan kulit mereka akan terbakar matahari.

\section{E. Simpulan \& Saran}

\section{i. Simpulan}

Berdasarkan penelitian di atas, penulis mengambil kesimpulan berikut: bahwa penyebab praktik pernikahan dini di Desa Cibunar, disebabkan oleh faktor ekonomi, faktor tempat tinggal serta lingkungan yang dapat memicu pernikahan tersebut. Analisis feminisme dalam pernikahan usia dini menggunakan teori feminisme liberal yang mana dalam hal ini ditandai dengan penekanan pada hak individu dan kesempatan bahwa perempuan harus memperjuangkan dirinya untuk dapat kedudukan yang sama seperti halnya laki-laki. Perempuan harus dikembalikan pada posisinya sebagaimana manusia memiliki hak sama seperti halnya laki-laki.

\section{ii. Saran}

Pernikahan usia dini memang tidak dilarang dalam agama, tapi ada baiknya pernikahan dilakukan apabila telah memenuhi syarat pernikahan ideal, yakni cukup umur dan matang secara mental, juga telah siap dalam menghadapi segala hal dalam membina agar kedepannya tidak mengalami kegagalan. 


\section{DAFTAR PUSTAKA}

Abdulkadir Muhammad, Hukum Perdata Indonesia. (Bandung: PT. Citra Aditya Bakti, 2000).

Abdurrahman Fatoni, Metodologi Penelitian dan Teknik Penyusunan Skripsi, (Jakarta: PT. Rinekha Cipta, 2006).

Ahmad Tanzeh dan Sugiyono, Dasar-dasar Penelitian, (Surabaya: Elkaf, 2006).

Amir Syarifuddin, Hukum Perkawinan Islam di Indonesia, (Jakarta: Kencana, 2006).

Asmaeni Azis, Feminisme Profetik, (Yogyakarta: Kreasi Wacana, 2007).

Beasley Chris, What is Feminism?: An Introduction to Feminist Theory.

De Beauvoir Simone, Second Sex: Fakta dan Mitos (Surabaya: Pustaka PromotheA, 2003).

Dep Dikbud, Kamus Besar Bahasa Indonesia, Cet III, Edisi II (Jakarta: Balai Pustaka, 1994).

Departemen Pendidikan Nasional, Kamus Besar Bahasa Indonesia, (Jakarta: Balai Pustaka, 1990).

Departemen Agama RI, Undang-undang no. 1 tahun 1974 tentang Perkawinan dan Peraturan Pemerintah Nomor 9 tahun 1975, Jakarta 2004.

Deddy Mulyana, Metodologi Penelitian Kualitatif, (Bandung: Remaja Rosdakarya, 2004).

Dr. Surtiretna, Cucu, Bimbingan Seks Suami Istri Pandangan Islam dan Medis, cet, 1 s.d 9 (Bandung: PT Remaja Rosdakarya, 2002).

Euis Amalia dkk, Pengantar Kajian Gender (Jakarta: Pusat Studi Wanita UIN Syarif Hidayatullah, 2003).

Gadis Arivia, Filsafat Berspektif Feminisme, (Jakarta Selatan: Yayasan Jurnal Perempun, 2003).

Kamla Bashin dan Night Said Khan, Persoalan Pokok Mengenai Feminisme dan Relevansinya, (PT. Gramedia Pustaka Utama, Jakarta 1995).

Komariah Ridwan, Statistika Untuk Lembaga dan Instansi Pemerintah/Swasta, (Bandung: Alfabeta, 2004).

Lukman A, Irfan, Nikah, (Yogyakarta: PT. Pustaka Insan Madani, 2007).

Lexy J. Moeloeng, Metodologi Penelitian Kualitatif, (Bandung: PT Remaja Rosdakarya, 2006).

Maggie Humm, Ensiklopedia Femisme, (Yogyakarta: Pajar Pustaka Baru, 2002) Mubarok, Ahmad. Psikologi Keluarga, Dari Keluarga Sakinah Dan Keluarga Bangsa. PT. Bina Rena Pariwara, Jakarta, Cet 1. 2005. 
Mansour Fakih, Menggeser Konsepsi Gender Dan Tranformasi Sosial (Yogyakarta: Pustaka Pelajar, 1995)

Muhammad, Husein. Fiqh Perempuan. (Yogyakarta: Lkis, 2001)

Manam, Abdul, Aneka Masalah Hukum Perdata Islam Indonesia, (Jakarta: Kencana Prenada Group, 2006)

Muhammad Fauzhil Adhim, Indahnya Pernikahan Dini, cet ke- 2 (Jakarta: Gema Insani Press, 2002)

Nural Zuriah, Metodologi Penelitian Sosial dan Pendidikan, Jakarta: PT Bumi Aksara, 2006)

Peraturan Pemerintah Republik Indonesia Nomor 9 Tahun 1975 tentang Pelaksanaan Undang-Undang Pekawinan

Rosemarie Putnam Tong, Feminst Thought, diterjemahkan oleh Aquarini Priyatna Prabasmoro, (Yogyakarta, Jalasutra, 1998)

Sati, D.A Pakih, Panduan Lengkap Pernikahan (Yogyakarta: BENING, 2011)

Sarwono S, Psikologis Remaja. (Jakarta: PT Rajagrafindo Persada 2007)

Slamet, Abidin. Fiqh Munaqahat, (Bandung: CV Pustaka Setia, 1999)

S. Munir, Figh Syari'ah, (Solo: Amanda, 2007)

Sayyid, Sabiq, Fiqh Assunnah, Cet IV jilid 2 (Beirut: Beirut Dar al- Fikr,1981)

Soemiyati, Hukum Perkawinan Islam dan Undang-Undang Perkawinan, (Yogyakarta: Liberti, 1982)

Sri Rahayu Hadiutomo, Psikologi Perkembangan dan Bagian-bagiannya, (Yogjakarta: Gajah Mada Press, 1989)

Sugiyono, Metode Penelitian Kuantitatif, Kualitatif dan REDD, (Alfabeta 2008, Cet. IV)

Supardi, Metodologi Penelitian Ekonomi dan Bisnis, (Yogyakarta: UII Press, 2005),

Taqqiyuddin An Nabhani, An Nizham Al Ijtima'i Fi Al Islam. (Bandung: PT Al-Ma'rif 1990)

Alfiyah. 2010. Sebab-sebab Pernikahan Dini.

http// alfiyah23.student.umm.ac.id. Diakses tanggal 25 Januari 2018.

Responden-Pengertian, Contoh, Kelebihan, Kekurangan, Wawancara”, Pengertian, diakses dari http://pengertian.blogspot.co.id/2012/06/responden-pengertiancontoh-kelebihan.html

KBBI, Kamus Besar Bahasa Indonesia (KBBI). (Online) Available at: https://kbbi.web.id/dampak

Fenomena Pernikahan Dini dan Solusinya https://student.cnnindonesia.com/inspirasi/20160318142526322-118315/fenomena-pernikahan-dini-dan-solusinya/ 